\title{
BOR DERGISI

\section{Genipin ile çapraz bağlı bor katkılı polisakkarit kompleks sentezi ve karakterizasyonu}

Elif Ant Bursali ${ }^{\oplus 1}{ }^{*}$

1Dokuz Eylül Üniversitesi, Fen Fakültesi, Kimya Bölümü, İzmir, 35390 Türkiye

\section{MAKALE BILGISi}

Makale Geçmişi:

İlk gönderi 28 Mayıs 2021

Kabul 8 Ekim 2021

Online 31 Aralık 2021

Araştırma Makalesi

DOI: $10.30728 /$ boron. 944413

Anahtar kelimeler:

Bor

Çapraz bağlama

Genipin

Nişasta

\begin{abstract}
ÖZET
Çevre dostu, yenilenebilir, biyobozunur, oldukça ucuz malzemeler olan doğal polisakkaritlerin performans özellikleri çapraz bağlanma ve hidrofobik sübstitüsyon gibi bazı kimyasal modifikasyonlar ile iyileştirilebilir. Çapraz bağlanma ile ardışık polisakkarit zincirlerinde rastgele bölgelerde molekül içi ve moleküller arası eter ve ester bağları oluşur. Böylece elde edilen malzemelerin asidik ortama ve ısıya karşı dirençleri artarken, viskozite ve çözünürlükleri azalır. Gardenya meyve özünde bulunan ve doğal bir bileşik olan genipin toksik özellik göstermediği için çapraz bağlayıcı olarak tercih edilmektedir. Bu çalışmanın amacı, genipin ile çapraz bağlanarak modifiye edilmiş nişasta ve modifiye edilmemiş nişastanın bor katkılı komplekslerinin hazırlanması ve karakterizasyonlarının yapılmasıdır. Bu amaçla taramalı elektron mikroskopu, X-ışınları kırınımı, Fourier dönüşümlü kızı̈ötesi spektroskopisi, termogravimetrik analiz yöntemleri kullanılmış ve elde edilen toz halindeki kompleksler için çözünürlük testleri de gerçekleştirilmiştir.
\end{abstract}

\section{Synthesis and characterization of boron doped polysaccharide complex cross-linked by genipin}

\section{ARTICLE INFO}

Article History:

Received May 28, 2021

Accepted October 8, 2021

Available online December 31, 2021

Research Article

DOI: $10.30728 /$ boron.944413

\section{Keywords:}

Boron

Crosslinking

Genipin

Starch

\begin{abstract}
Performance properties of natural polysaccharides which are environmentally friendly, renewable, biodegradable, fairly inexpensive, can be altered by some chemical modifications such as crosslinking and hydrophobic substitution. Intramolecular and intermolecular ether and ester bonds at random sites in sequential polysaccharide chains are formed with crosslinking. Thus, while the resistance of obtained materials against acidic environment and heat increase, their viscosity and solubility decrease. Genipin, a natural compound found in the Gardenia fruit extract, is preferred as a cross linker because it is non-toxic. Aim of this study is preparation and characterization of boron-doped complexes of unmodified starch and starch modified by crosslinking with genipin. For this purpose, scanning electron microscope, X-ray diffraction, Fourier transform infrared spectroscopy, thermogravimetric analysis methods have been used and solubility tests have been also performed for the obtained powder complexes.
\end{abstract}

\section{Giriş (Introduction)}

Polisakkaritler, biyolojik olarak parçalanabilir yani doğada birikimi güç olan bileşiklerdir ve çeşitli alanlardaki kullanımları çevrenin korunmasında önemli bir rol oynayabilir [1]. Yenilenebilir, biyobozunur, bol miktarda bulunan, nispeten ucuz bir malzeme olan nişasta suda çözünür bir polisakkarittir ve nişastanın performans özellikleri çapraz bağlanma, hidrofobik yer değiştirme gibi bazı kimyasal modifikasyonlarla düzeltilebilir [2, 3].
Çapraz bağlanmış nişasta, bitişik nişasta zincirlerinin glikoz kalıntıları arasında rastgele yerleşmelerle moleküller arası eter veya ester bağı oluşturma yeteneğindeki bir veya daha fazla çok fonksiyonlu reaktif ile iyileştirilmiş nişastadır [4, 5]. Çapraz bağlı nişastanın özellikleri kullanılan reaktifin kimyasal doğasına, nişasta kaynağına, reaktif derişimine, $\mathrm{pH}$ değerine, tepkime zamanı ve sıcaklığa bağlıdır [6, 7]. Çapraz bağlanma, nişasta moleküllerinin rastgele konumlarına moleküliçi ve moleküler-arası bağlanmalar yaparak nişastanın 
özelliklerini modifiye eden, asidik ortam ve ısıya karşı daha dirençli yapan önemli bir tekniktir [8, 9]. Çapraz bağlanma, su ile nişastanın etkileşimini sınırlama eğilimindedir ve nem ile basınca maruz kalma sırasında nişasta bazlı biyolojik olarak parçalanabilen malzemelerin yapısal bütünlüğünü sağlar [10, 11]. Fosfor oksiklorür $\left(\mathrm{POCl}_{3}\right)$ [12], sodyum trimetafosfat (STMP) [13], sodyum tripolifosfat (STPP) [14], epiklorohidrin (EPI) [5], glutaraldehit (GA) [15] gibi çok işlevli kimyasallar, çapraz bağlayıcı olarak yaygın biçimde kullanılır [1618].

Anti-depresan, antidiyabetik, antikanser, anti-enflamatuar, antibakteriyel bir madde olan genipin, Genipa americana ve Gardenia jasminoides ellis meyvelerinden geniposide ekstraksiyonu sonrasında Penicillum nigricans tarafından $\beta$-D-glukozidaz enzimiyle hidrolize edilmesi ile elde edilir. Genipin, çapraz bağlayıcı olarak kullanılabilen doğal bir bileşiktir [19-21]. Genipinin, yaygın kullanılan çapraz bağlayıcılar ile kıyaslandığı birçok çalışma vardır ki bu çalışmalarda genipinin daha düşük sitotoksisite ve daha yüksek biyo uyumluluk gösterdiği ortaya koyulmuştur [22-27].

Bitkiler, hayvanlar ve insanlar için önemli bir mikrobesin maddesi olan bor, kolay elde edilebilir, ucuz ve düşük toksisiteye sahip bir elementtir. Önerilen bor derişimi, içme ve sulama suları için sırasıyla 0,3 ve 0,75 $\mathrm{mg} . \mathrm{dm}^{-3}$ olarak ifade edilebilir [28]. Bor, yaygın kullanım alanının yanı sıra birçok polimere katkı malzemesi olma potansiyeline sahiptir [29-32]. Bor, hidroksil grupları içeren nişasta gibi polisakkaritler ile ester bağı oluşturabilir. Bor-ester bağlarını kullanarak nişasta nanopartikülleri oluşturmak son yıllarda karbonhidrat nanoparçaçık araştırmalarına katkı sağlayan bir stratejidir [33, 34]. Bor katkısı nişastanın, mekanik, elektriksel, antibakteriyel, antifungal özellikleri ile termal kararlılık ve esnekliğini iyileştirici rol oynar [29, 35, 36].

Bu çalışmada biyouyumluluğu yüksek doğal bir bileşik olan genipin ile çapraz bağlanarak modifiye edilmiş nişasta ve bor katkılı çapraz bağlı nişasta komplekslerinin sentezi hedeflenmiştir. Elde edilen kompleksler taramalı elektron mikroskopu (SEM), X-ışınları kırınımı (XRD), fourier dönüşümlü kızılötesi spektroskopisi (FTIR), termogravimetrik (TG/DTG) analiz yöntemleri kullanılarak karakterize edilmiştir. Ayrıca, çapraz bağ- lanma ile birlikte nişastanın çözünürlüğünde bir azalma beklendiği için tüm komplekslere çözünürlük testleri uygulanmıştır.

\section{Malzemeler ve Yöntemler (Materials and Methods)}

\subsection{Malzemeler (Materials)}

Patates nişastası (S) (Fluka 85643), borik asit (BA) (Merck 1.00160) ve diğer bütün kimyasal maddeler analitik saflıkta olup ayrıca saflaştırma yapılmamıştır. Tüm deneylerde, nişasta kullanılmadan önce etüvde 2 saat $105^{\circ} \mathrm{C}$ sıcaklıkta kurutulmuştur.

Deneyler sırasında Denver 215 model pH metre, Heildolp MR 3001 model manyetik karıştırıcı, Retsch PM 200 model öğütücü ve Polyscience 9006 model soğutma-ısıtma sirkülasyonlu su banyosu kullanılmıştır.

\section{2. Çapraz bağlı polisakkaritin hazırlanması (Pre- paration of cross-linked polysaccharide)}

$10 \mathrm{~g}$ nişasta $20 \mathrm{~cm}^{3}$ saf su ile karıştırılarak viskoz bir çözelti elde edildi (\%50 w/v). Çözelti, $2 \mathrm{~mol} \mathrm{dm}^{-3} \mathrm{NaOH}$ ile $\mathrm{pH}=8$ 'e ayarlandı. Daha sonra $0,25 \mathrm{~g}$ genipinin 5 $\mathrm{cm}^{3}$ alkolde çözünmesiyle hazırlanan çözeltiden 1,334 $\mathrm{cm}^{3}$ genipin çözeltisi, çapraz bağlayıcı olarak viskoz çözeltiye eklendi (Şekil 1). Son karışım $45^{\circ} \mathrm{C}$ sıcaklıkta, 350 rpm'de 2 saat boyunca karıştırıldı. Ardından karışım diyaliz membran kullanılarak saf su ile yıkandı ve $\mathrm{pH}$ kontrolü yapıldıktan sonra diyaliz membrandan üst faz dekante edildi. Elde edilen kompleks (S-GNP) 24 saat vakum etüvde $45^{\circ} \mathrm{C}$ 'ta kurutuldu ve daha sonra öğütüldü.

\subsection{Bor katkılı çapraz bağlı polisakkaritin hazırlan- ması (Preparation of cross-linked boron doped poly- saccharide)}

Borik asitteki bor atomu elektron eksikliği olan bir atom olduğu için elektron verebilen herhangi bir gruba karşı çok reaktiftir ve elektron alıcısı işlevi gösterip tetrahedral borat anyonunu oluşturur. $\mathrm{pH}=8$ civarında ortamda $\mathrm{B}(\mathrm{OH})_{3}$ ve $\mathrm{B}(\mathrm{OH})_{4}^{-}$bulunmaktadır. Bir polialkol olan nişastanın bu gruplar ile ester oluşturma tepkimesi [37] için önerilen mekanizma Şekil 2'de verilmiştir. Yapıya bor katkısı nişastanın hem mekanik
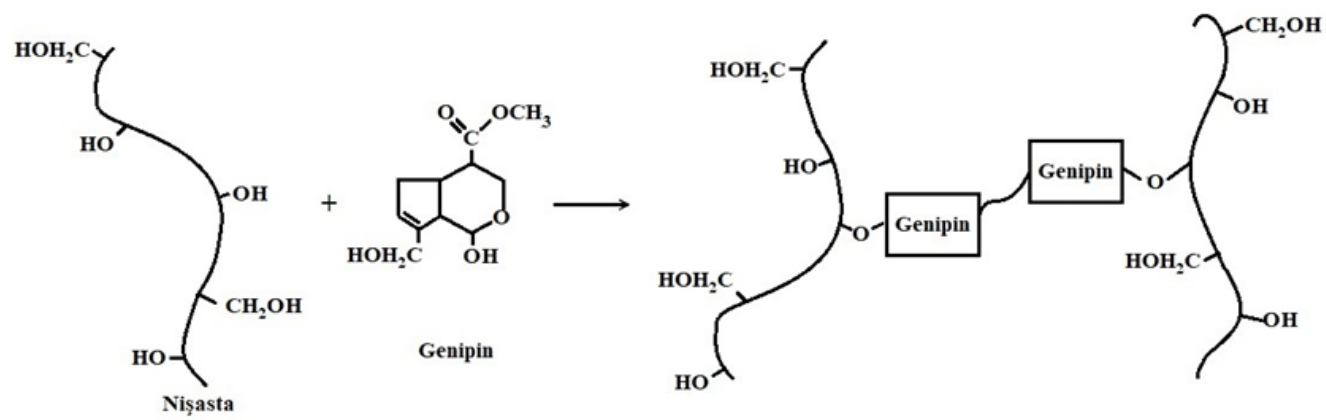

Şekil 1. Nişastanın genipin ile çapraz bağlanması için önerilen tepkime mekanizması (Proposed reaction mechanism for cross linking of starch by genipin). 


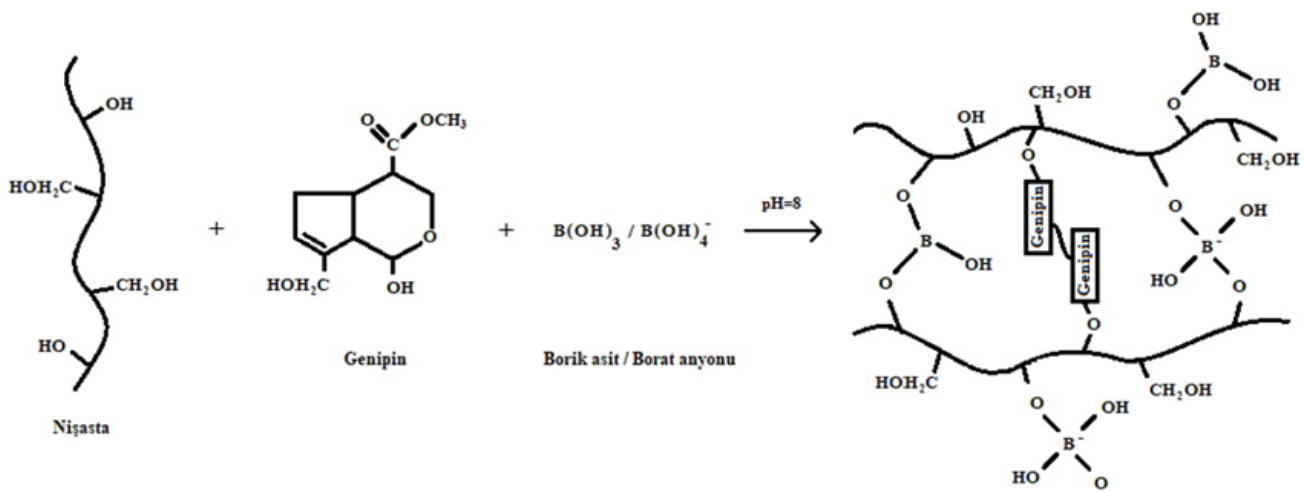

Şekil 2. Genipin ile çapraz bağıı bor katkılı nişasta sentezi için önerilen tepkime mekanizması (Proposed reaction mechanism for synthesis of boron-doped starch cross-linked by genipin).

hem de termal kararlılığını arttııcı rol oynamaktadır. Bu amaçla, $20 \mathrm{~cm}^{3}$ saf suda $0,075 \mathrm{~g} \mathrm{BA} \mathrm{çözüldü} \mathrm{ve}$ bu çözeltiye $10 \mathrm{~g}$ nişasta eklendi. Çözelti, $2 \mathrm{~mol} \mathrm{dm}^{-3}$ $\mathrm{NaOH}$ ile $\mathrm{pH}=8$ 'e ayarlandı. Daha sonra karışıma $\% 5^{\prime}$ lik $1,334 \mathrm{~cm}^{3}$ genipin çözeltisi eklendi ve $45^{\circ} \mathrm{C}$ sıcaklıkta 750 rpm'de 2 saat karıştırma işlemine devam edildi. Karışım diyaliz membranda saf su ile yıkandı ve $\mathrm{pH}$ kontrolü yapıldı. Üst faz dekante edildikten sonra kompleks (S-GNP-BA) 24 saat boyunca vakum etüvde $45^{\circ} \mathrm{C}$ 'ta kurutuldu ve daha sonra öğütüldü.

\subsection{Komplekslerin yapı analizi (Structure analysis of complexes)}

Komplekslerin karakterize edilmesinde XRD, FTIR, SEM ve TG/DTG yöntemleri kullanıldı. XRD analizleri Rigaku - Rint 2200/PC (Ultima 3) kırınım metresi ile Cu $\mathrm{K}_{\alpha}$ radyasyonu $\left(\lambda-\mathrm{K}_{\alpha 1}=1,54 \AA\right)$ kullanılarak 0,4 derece/ dakika tarama hızında $10-40^{\circ}$ aralıkta gerçekleştirildi. FTIR analizi için, Perkin-Elmer Spectrum BX-II Model FTIR spektrofotometresi kullanıldı. $\mathrm{KBr}$ ile hazırlanan pelletler FTIR spektroskopisi ile $4000-400 \mathrm{~cm}^{-1}$ dalga sayısı aralığında $4 \mathrm{~cm}^{-1}$ çözünürlükte ve 25 tarama yapılarak analiz edildi. SEM analizleri, FEI Quanta FEG 250 SEM Taramalı Elektron Mikroskobu ile yapıldı ve komplekslerin yüzeyleri analiz öncesi altın ile kaplandı. Komplekslerin TG/DTG analizleri, Perkin Elmer Diamond TG/DTG cihazı ile azot atmosferi altında gerçekleştirildi.

\subsection{Sentezlenen kompleksler için çözünürlük test- leri (Solubility tests for synthesized complexes)}

Çapraz bağlanmanın nişastanın çözünürlüğüne etkisini incelemek amacıyla çözünürlük testleri gerçekleştirildi. Sentezlenmiş tüm kompleksler ayrı ayrı yaklaşık $0,1 \mathrm{~g}$ tartıldı ve $10 \mathrm{~cm}^{3}$ ultra saf su içeren beherlerde oda sıcaklığında 3 saat, 450 rpm'de karıştırıldı. Daha sonra çözeltiler süzüldü ve katı ürün sabit bir ağırlığa kadar $50^{\circ} \mathrm{C}$ sıcaklıkta vakum etüvde kurutuldu. Çözünürlük hesabı, Eş. 1'e göre yapıldı. Burada $W_{i}$ ürünün başlangıç ağırlığı, $W_{d}$ ise son ağırlığıdır.

$$
\% \text { Çözünürlük }=\left[\frac{\left(\mathrm{W}_{\mathrm{i}}-\mathrm{W}_{\mathrm{d}}\right)}{\mathrm{W}_{\mathrm{i}}}\right] \cdot 100
$$

\section{Sonuçlar ve Tartışma (Results and Discussion)}

\subsection{XRD analizi (XRD analysis)}

Komplekslerin X-ışını kırınım desenleri ve XRD sonuçları Şekil 3 ve Tablo 1'de gösterilmiştir. Hem kimyasal (amiloz ve amilopektin) hem de fiziksel (kristal ve kristal olmayan bölgeler) olarak heterojen olan nişasta granülleri ile bor içerikli ve çapraz bağlı nişasta komplekslerinin XRD kırınım desenleri incelendiğinde, nişastanın kristalliği ile çapraz bağlı nişastaların kristalliği arasında oldukça fark olduğu görülmektedir.

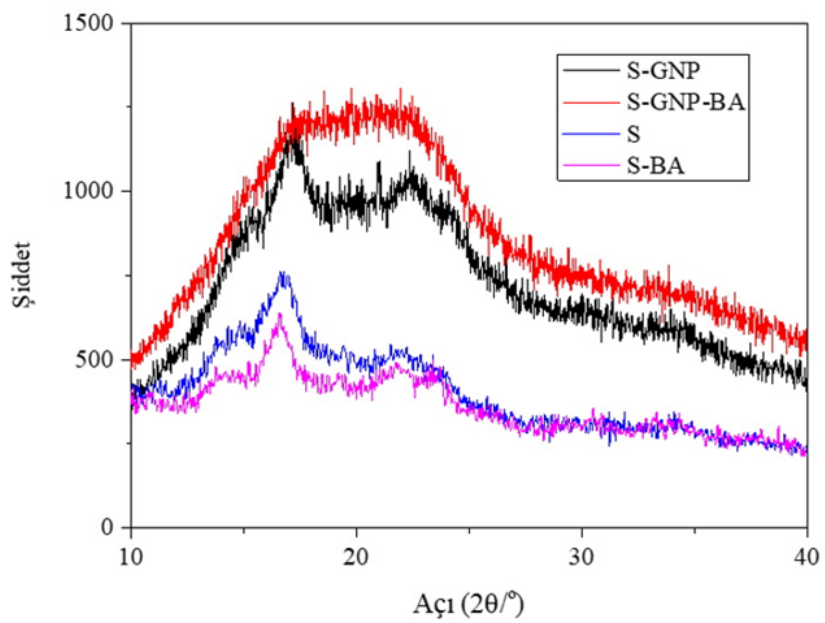

Şekil 3. Sentezlenen komplekslerin XRD desenleri (XRD patterns of synthesized complexes).

Tablo 1. Sentezlenen komplekslerin XRD sonuçları (XRD results of synthesized complexes).

\begin{tabular}{lc}
\hline Numune & $\mathbf{2} \boldsymbol{\Theta}\left(^{\circ}\right)$ \\
\hline $\mathbf{S}$ & 16,7 \\
& 22,0 \\
\hline S-BA & 16,6 \\
& 21,9 \\
& 23,5 \\
\hline S-GNP & 17,3 \\
& 20,9 \\
& 22,4 \\
& 23,9 \\
\hline S-GNP-BA & $17,3-23,0$ (yayvan pik) \\
\hline
\end{tabular}


Yapı temelde amorf hale dönmektedir. BA bağlanmadan önceki nişastanın kristal pik alanıyla BA bağlanmış nişastanın kristal pik alanı da büyük farklılık göstermektedir. BA bu durumda çapraz bağlanmayı arttırıp kristallenme etkisini düşüren ve amorf yapıya giden bir çapraz bağlayıcı olarak düşünülebilir.

B tipi kristal yapıya sahip nişastanın $2 \theta=17,0^{\circ}$ ve $2 \theta=22,0^{\circ}$ de gözlenen piklerinin şiddetleri, Şekil 3 ve Tablo 1 deki veriler, literatür ile uyum içerisindedir. Nişastanın kristallik dereceleri ile ilgili çalışmalar literatürlerde verilmektedir. (JCPDS Kart No 43-1858) [38-40]. Diğer taraftan S-BA'da bu piklerin şiddetleri azalırken genipin ile çapraz bağlandığında artmıştır. S-GNP-BA da ise yayvan bir pik haline gelmiştir. Tek kristal piki veren BA'in piklerinin bor içerikli komplekslerde görülememesinin nedeni literatürde de görüldüğü üzere kompleksleşme sonucu ortamda çok az BA kalması veya hiç kalmaması şeklinde değerlendirilmiştir [41].

\subsection{FTIR analizi (FTIR analysis)}

Kompleksler için elde edilen FTIR spektrumları Şekil 4 'te verilmiştir. Hidrojen bağı yapan hidroksil grupları nedeniyle nişastada $3390 \mathrm{~cm}^{-1}$ olarak gözlenen geniş band, S-BA için $3409 \mathrm{~cm}^{-1}$, S-GNP için $3401 \mathrm{~cm}^{-1}$ ve S-GNP-BA için $3411 \mathrm{~cm}^{-1}$ olarak gözlenmiştir. Nişasta ve diğer tüm bileşiklerde alifatik C-H gerilme titreşimleri $2927 \mathrm{~cm}^{-1}$ 'de gözlenmiştir. Nişastanın C-H eğilme titreşimine ait $1372 \mathrm{~cm}^{-1}$ görülen bandın şiddeti tüm komplekslerde artış göstermiştir. Nişastanın C-O-C gerilme titreşimleri olan karakteristik absorbsiyon bantları literatürde karşılaşıldığı gibi 1159-1016 cm-1 civarında görülmüştür [42]. S-BA ve S-GNP-BA'nın spektrumlarında gözlenen bandların benzer olduğu ve çapraz bağlanma ile bu bandların frekanslarında artmalar ve kaymalar olduğu gözlenmiştir. BA spektrumunda gözlenen $1500-1100 \mathrm{~cm}^{-1}$ 'deki B-O gerilme karakteristik bandları, $900-700 \mathrm{~cm}^{-1}$ civarındaki O-B-O bandları ve $650 \mathrm{~cm}^{-1}$ civarındaki B-O bozunma bandları sentezlenen S-BA ve S-GNP-BA komplekslerinde görülmemiştir. Bu sonuç BA ile kompleksleşmenin tam olarak gerçekleştiğini göstermektedir.

\subsection{SEM analizi (SEM analysis)}

Nişasta ve elde edilen komplekslere ait SEM görüntüleri Şekil 5'te gösterilmiştir. Nişasta parçacıklarının şekli ve büyüklüğü nişastanın kaynağına bağlıdır. Nişasta parçacıkları kullanılan kaynağa göre 5-100 $\mu \mathrm{m}$ arasında değişkenlik gösterebilir [43]. Komplekslerin SEM görüntülerine bakılarak nişastadaki düzgün, pürüzsüz oval şekilli ve irili-ufaklı kürelerin S-BA kompleksinde BA etkisiyle büyük bir kümeleşme gösterdiği söylenebilir. S-GNP kompleksinde kümeleşmeye rastlanmamakla birlikte kürelerin boyutunda nişastaya göre bir küçülme gözlenirken, S-GNP-BA kompleksinde ise küçük parçacıklar şeklinde ayrılmalar gösteren bir kümeleşme dikkat çekmektedir. Elde edilen sonuçlar, pürüzsüz, oval ya da yuvarlak şekle sahip doğal patates nişastasının granüllerinin çeşitli derişimlerdeki farklı çapraz bağlayıcılar ile etkileştirildiğinde hafif pürüzlü yüzeyler ve boşluklar sergilediğini gösteren literatürdeki çalışmalar ile uyumludur [42, 44, 45].

\subsection{TG/DTG analizi (TG/DTG analysis)}

Komplekslerin termal kararlılığının değerlendirilmesi açısından, elde edilen termogramlar (Şekil 6) ve termogravimetrik analiz verileri (Tablo 2) incelendiğinde nişasta ve diğer tüm toz bileşiklerin iki basamakta bozunma gösterdiği görülmektedir. Birinci basamak tüm nişasta komplekslerinde $55-85^{\circ} \mathrm{C}$ sıcaklık aralığında adsorplanan suyun buharlaşmasını gösterir ve maksimum \%12 kütle kaybını içermektedir. Diğer ayrışma basamakları ise $289-301^{\circ} \mathrm{C}$ sıcaklık aralığında tüm nişasta, çapraz bağlı ve bor içerikli komplekslerin termal bozunmasına aittir ve maksimum \%43-76 kütle kaybı görülmektedir.

Nişastanın $299^{\circ} \mathrm{C}$ 'ta gerçekleşen ikinci bozunma basamağının S-BA'da $289^{\circ} \mathrm{C}$ 'ta gerçekleştiği ve BA kat-

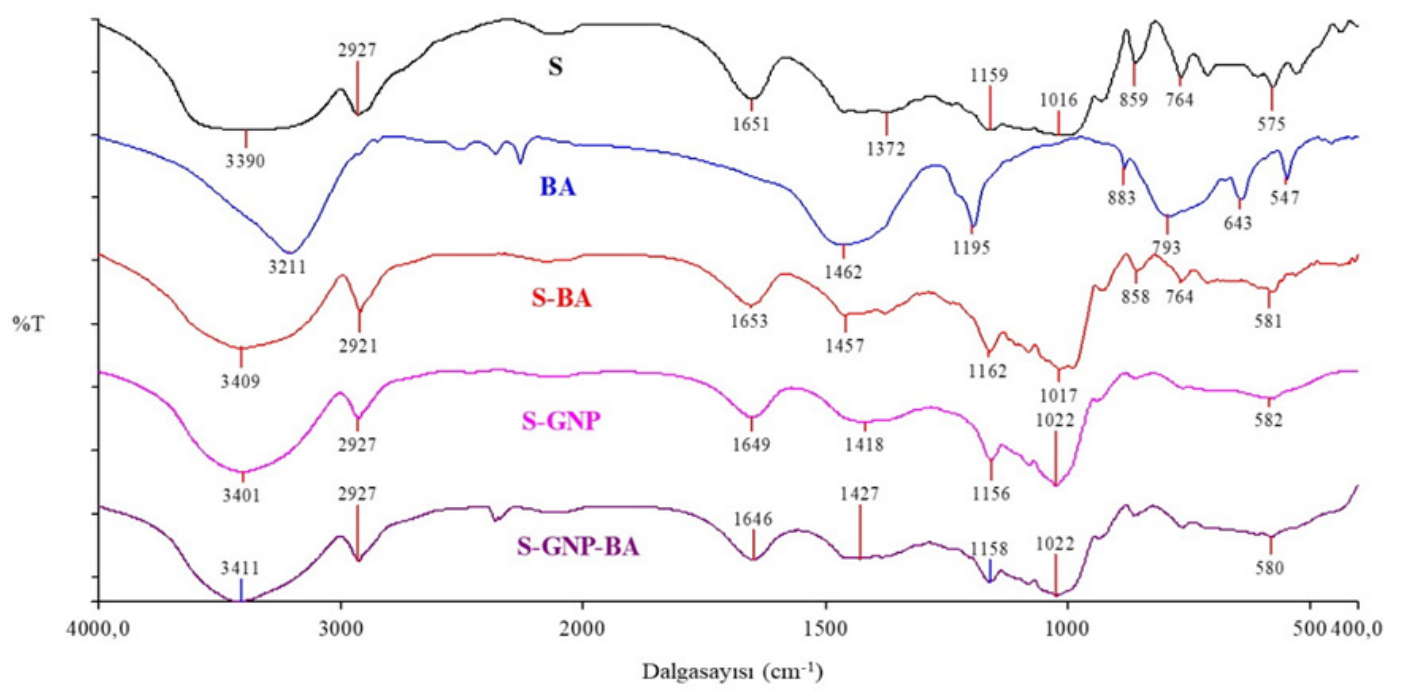

Şekil 4. Komplekslerin FTIR spektrumları (FTIR spectra of complexes). 


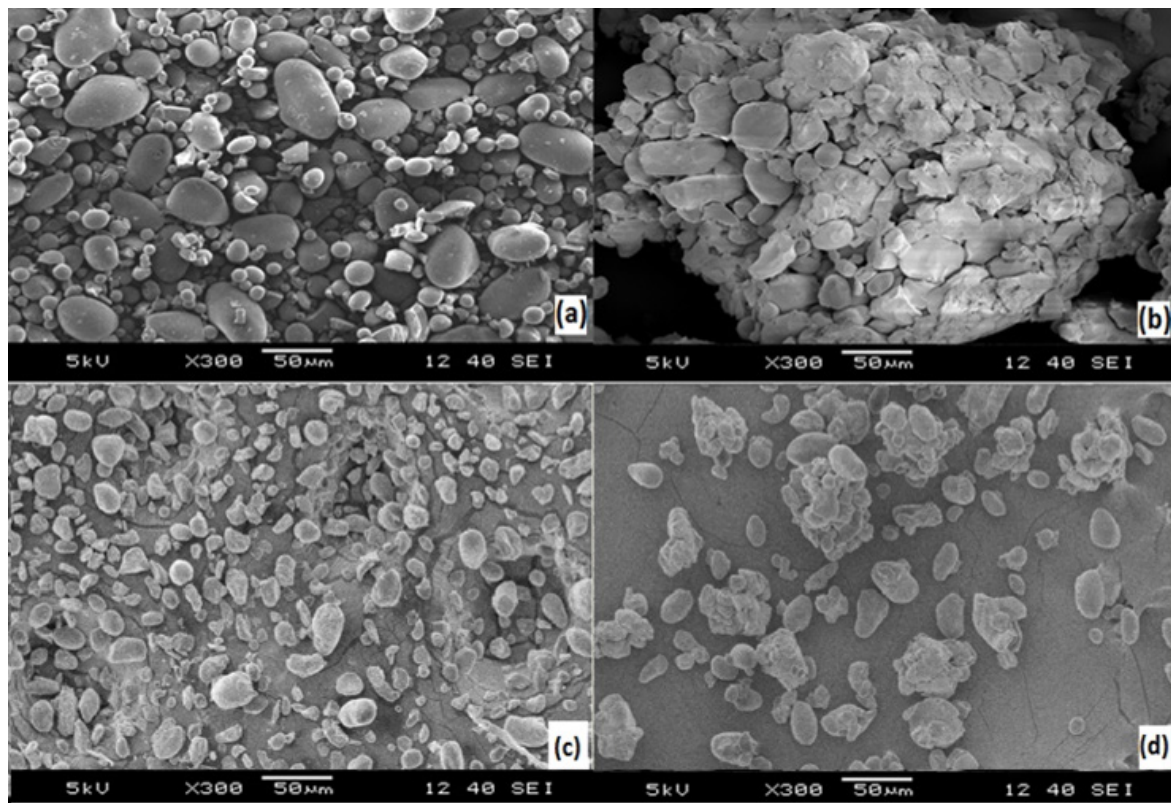

Şekil 5. Sentezlenen komplekslerin x300 büyütmedeki SEM görüntüleri.(a) S, (b) S-BA, (c) S-GNP, (d) S-GNP-BA (SEM images of synthesized complexes at x300 magnification (a) S, (b) S-BA, (c) S-GNP, (d) S-GNP-BA).

kısının nişastanın bozunma sıcaklığını azaltıcı yönde etki yaptığı, oysa GNP içeren komplekslerde nişastanın bozunma sıcaklığının yani termal kararııı̆ının çapraz bağlanma etkisiyle $1-2^{\circ} \mathrm{C}$ artığı gözlenmektedir. Çapraz bağlanmada kullanılan çapraz bağlayıcının türü ve konsantrasyonunun termal özelliklerdeki değişimin derecesini önemli ölçüde etkilediği bilinmektedir [46]. Literatürde nişastanın genipin ile çapraz bağlandığı bor katkılı bir çalışma bulunmamaktadır, ancak fosfor oksiklorür, sodyum trimetafosfat ve sodyum tripolifosfat gibi reaktifler ile çapraz bağı nişastanın termal kararııı̆ının doğal nişastaya göre arttığını belirten çalışmalar mevcuttur $[47,48]$.

\section{5. Çözünürlük testleri (Solubility tests)}

Polisakkaritlerin çapraz bağlanması, polisakkarit zincirleri arasındaki moleküller arası köprülerin oluşumuyla polisakkaritin çözünürlüğünü azaltan en yaygın yollardan biridir. Kaur ve ark., epiklorhidrin ve fosforil klorür ile çapraz bağladıkları patates nişastasının doğal nişastadan daha düşük çözünürlük gösterdiğini belirtirken [45], Kim ve ark. sodyum trimetafosfat ve sodyum tripolifosfat ile çapraz bağladıkları nişastanın çözünürlüğünün uygulanan farklı sıcaklıklardan bağımsız olarak sabit kaldığını ve çözünürlüğün doğal nişastaya oranla önemli ölçüde düşük olduğunu
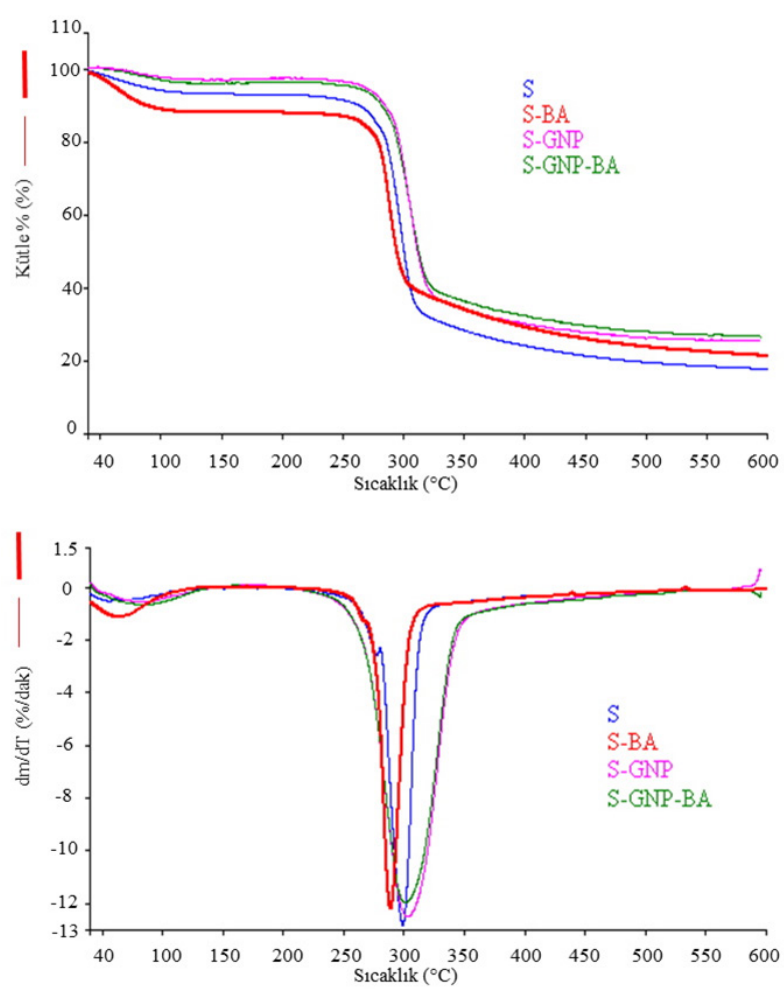

Şekil 6. Sentezlenen komplekslerin TG/DTG eğrileri (TG/ DTG curves of synthesized complexes).

Tablo 2. Sentezlenen komplekslerin TG/DTG analiz verileri (TG/DTG analysis data of synthesized complexes).

\begin{tabular}{lcccc}
\hline \multirow{2}{*}{ Örnek } & \multicolumn{2}{c}{ 1. Basamak } & \multicolumn{2}{c}{ 2. Basamak } \\
\cline { 2 - 5 } & $\begin{array}{c}\text { DTG Maksimum } \\
\text { Sıcaklık }\left({ }^{\circ} \mathrm{C}\right)\end{array}$ & $\begin{array}{c}\text { Kütle } \\
\text { Kaybı (\%) }\end{array}$ & $\begin{array}{c}\text { DTG Maksimum } \\
\text { Sıcaklık }\left({ }^{\circ} \mathrm{C}\right)\end{array}$ & $\begin{array}{c}\text { Kütle } \\
\text { Kaybı (\%) }\end{array}$ \\
\hline S & 55 & 7 & 299 & 76 \\
S-BA & 63 & 12 & 289 & 67 \\
S-GNP & 72 & 3 & 301 & 43 \\
S-GNP-BA & 85 & 5 & 300 & 70 \\
\hline
\end{tabular}


bildirmişlerdir [49]. Kim ve Yoo ise, doğal tatı patates nişastanın \%23,7 olan çözünürlük değerinin farklı derişimlerde fosfor oksiklorür ile çapraz bağlanma sonucu azalarak \%5,5 ile \%10,5 aralığında değer aldığını göstermişlerdir [50].

Gerçekleştirilen çözünürlük testleri sonucunda (Tablo 3 ), bor içerikli ve genipin ile çapraz bağlı nişasta komplekslerinin çözünürlügünün nişastadan daha az olduğu görülmüştür ve çapraz bağlayıcı miktarının artmasıyla çözünürlüğün daha fazla azaldığı söylenebilir. Çözünürlükteki bu değişim, nişastanın tüm çapraz bağlı komplekslerinde açıkça görülmektedir. En düşük çözünürlük \%1,58 olarak daha kuvvetli çapraz bağlanma etkisiyle S-GNP-BA kompleksinde gözlenmiştir.

Tablo 3. Komplekslerin çözünürlük değerleri. (Solubility values of complexes).

\begin{tabular}{lc}
\hline \multicolumn{1}{c}{ Örnek } & Çözünürlük (\%) \\
\hline S & 26,8 \\
S-BA & 25,7 \\
S-GNP & 4,67 \\
S-GNP-BA & 1,58 \\
\hline
\end{tabular}

\section{Sonuçlar (Conclusions)}

Çalışmada çapraz bağlayıcı olarak genipin içeren bor katkılı nişasta kompleksleri sentezlenerek bu komplekslerin yapıları çeşitli yöntemler ile aydınlatılmaya çalışılmış ve ayrıca tüm komplekslere çözünürlük testleri uygulanmıştır. Yarı kristal yapıya sahip nişastanın XRD deseninde yaklaşık olarak $2 \theta=17,0^{\circ}$ de görülen kuvvetli kııınım pikinin, çapraz bağı ı nişasta komplekslerinde giderek yayvanlaştığı ve çapraz bağlanma artıkça, piklerin şiddetinde azalma ve amorf yapıya giden bir genişleme olduğu gözlenmiştir $\left(2 \theta=17,0^{\circ}\right.$ $\left.23,0^{\circ}\right)$. TG/DTG sonuçlarına göre termal bozunma sıcaklıklarında gözlenen $1-2^{\circ} \mathrm{C}$ artış nişastanın termal kararlıı̆̆ının çapraz bağlanma etkisiyle arttığını gösterirken, SEM görüntüleri çapraz bağlanma ile meydana gelen morfolojik değişimleri ortaya koymuştur. Ayrıca sentezlenen tüm kompleksler nişastadan daha düşük çözünürlük göstermiştir. Çapraz bağlayıcı miktarının artması çözünürlüğü azaltıcı yönde etki etmiş ve nişastanın çözünürlüğü \%26,8'den \%1,58'e kadar azalmıştır.

\section{Teşekkür (Acknowledgement)}

Çalışmam süresince değerli katkılarından dolayı Prof. Dr. Mürüvvet Yurdakoç ve ayrıca yardımları için Burcu Yertep' e teşekkür ederim.

\section{Kaynaklar (References)}

[1] Gonçalves, I., Hernández, D., Cruz, C., Lopes, J., Barra, A., Nunes, C., Silva, J. A. L., Ferreira, P. \& Coimbra, M. A. (2021). Relevance of genipin networking on rheological, physical, and mechanical properties of starch-based formulations. Carbohydrate Polymers,

\section{$254,117236$.}

[2] Garcia, M. A. V. T., Garcia, C. F., \& Faraco, A. A. G. (2020). Pharmaceutical and biomedical applications of native and modified starch: A review. Starch-Stärke, 72(7-8), 1900270.

[3] Sagnelli, D., Hebelstrup, K. H., Leroy, E., Rolland-Sabaté, A., Guilois, S., Kirkensgaard, J. J., Mortensen, K., Lourdin, D. \& Blennow, A. (2016). Plant-crafted starches for bioplastics production. Carbohydrate Polymers, 152, 398-408.

[4] Durmus, Y., Anil, M., \& Simsek, S. (2021). Effects of hazelnut skin, cross-linked starch, and oxidized starch on wheat flour and dough quality. Journal of Food Processing and Preservation, 45(2), e14919.

[5] Mirmoghtadaie, L., Kadivar, M., \& Shahedi, M. (2009). Effects of cross-linking and acetylation on oat starch properties. Food Chemistry, 116(3), 709-713.

[6] Olayemi, B., Isimi, C. Y., Ekere, K., Isaac, A. J., Okoh, J. E., \& Emeje, M. (2021). Green Preparation of citric acid crosslinked Starch for improvement of physicochemical properties of Cyperus Starch. Turkish Journal of Pharmaceutical Sciences, 18(1), 34.

[7] Lim, S., \& Seib, P. A. (1993). Preparation and pasting properties of wheat and corn starch phosphates. Cereal Chemistry, 70, 137-137.

[8] Akinterinwa, A., Oladele, E., Adebayo, A., \& Ajayi, O. (2020). Synthesis of cross-linked carboxymethyl legume starch for adsorption of selected heavy metals from aqueous solutions. Advanced Journal of Chemical Sector A, 3, 594-611.

[9] Acquarone, V. M., \& Rao, M. A. (2003). Influence of sucrose on the rheology and granule size of cross-linked waxy maize starch dispersions heated at two temperatures. Carbohydrate Polymers, 51(4), 451-458.

[10] El-Tahlawy, K., Venditti, R. A., \& Pawlak, J. J. (2007). Aspects of the preparation of starch microcellular foam particles crosslinked with glutaraldehyde using a solvent exchange technique. Carbohydrate Polymers, 67(3), 319-331.

[11] Mehboob, S., Ali, T. M., Sheikh, M., \& Hasnain, A. (2020). Effects of cross linking and/or acetylation on sorghum starch and film characteristics. International Journal of Biological Macromolecules, 155, 786-794.

[12] Hirsch, J. B., \& Kokini, J. L. (2002). Understanding the mechanism of cross-linking agents (POCl3, STMP, and EPI) through swelling behavior and pasting properties of cross-linked waxy maize starches. Cereal Chemistry, 79(1), 102-107.

[13] Wattanachant, S., Muhammad, K. M. A. T., Hashim, D. M., \& Rahman, R. A. (2003). Effect of crosslinking reagents and hydroxypropylation levels on dual-modified sago starch properties. Food Chemistry, 80(4), 463471.

[14] Omojola, M. O., Manu, N., \& Thomas, S. A. (2012). Effect of cross linking on the physicochemical properties of cola starch. African Journal of Food Science, 6(4), 91-95.

[15] Musa, B. H., \& Hameed, N. J. (2021). Effect of crosslinking agent (glutaraldehyde) on the mechanical prop- 
erties of (PVA/Starch) blend and (PVA/PEG) binary blend films. In Journal of Physics: Conference Series, 1795(1), 012064

[16] Sharma, V., Kaur, M., Sandhu, K. S., \& Godara, S. K. (2020). Effect of cross-linking on physico-chemical, thermal, pasting, in vitro digestibility and film forming properties of Faba bean (Vicia faba L.) starch. International Journal of Biological Macromolecules, 159, 243249.

[17] Dong, H., \& Vasanthan, T. (2020). Amylase resistance of corn, faba bean, and field pea starches as influenced by three different phosphorylation (cross-linking) techniques. Food Hydrocolloids, 101, 105506.

[18] Hoover, R., Hughes, T., Chung, H. J., \& Liu, Q. (2010). Composition, molecular structure, properties, and modification of pulse starches: $A$ review. Food $R e-$ search International, 43(2), 399-413.

[19] Tavares, L., Flores, E. E. E., Rodrigues, R. C., Hertz, P. F., \& Noreña, C. P. Z. (2020). Effect of deacetylation degree of chitosan on rheological properties and physical chemical characteristics of genipin-crosslinked chitosan beads. Food Hydrocolloids, 106, 105876

[20] Zanjani, M. A. K., Ehsani, M. R., Tarzi, B. G., \& Sharifan, A. (2018). Promoting probiotics survival by microencapsualtion with Hylon starch and genipin crosslinked coatings in simulated gastro-intestinal condition and heat treatment. Iranian Journal of Pharmaceutical Research: IJPR, 17(2), 753.

[21] Khan, A., Salmieri, S., Fraschini, C., Bouchard, J., Riedl, B., \& Lacroix, M. (2014). Genipin cross-linked nanocomposite films for the immobilization of antimicrobial agent. ACS Applied Materials \& Interfaces, 6(17), 15232-15242.

[22] Liu, Y., Cai, Z., Sheng, L., Ma, M., Xu, Q., \& Jin, Y. (2019). Structure-property of crosslinked chitosan/ silica composite films modified by genipin and glutaraldehyde under alkaline conditions. Carbohydrate Polymers, 215, 348-357.

[23] Cui, L., Jia, J., Guo, Y., Liu, Y., \& Zhu, P. (2014). Preparation and characterization of IPN hydrogels composed of chitosan and gelatin cross-linked by genipin. Carbohydrate Polymers, 99, 31-38.

[24] Chiono, V., Pulieri, E., Vozzi, G., Ciardelli, G., Ahluwalia, A., \& Giusti, P. (2008). Genipin-crosslinked chitosan/gelatin blends for biomedical applications. Journal of Materials Science: Materials in Medicine, 19(2), 889-898.

[25] Sung, H. W., Huang, R. N., Huang, L. L., \& Tsai, C. C. (1999). In vitro evaluation of cytotoxicity of a naturally occurring cross-linking reagent for biological tissue fixation. Journal of Biomaterials Science, Polymer Edition, 10(1), 63-78.

[26] Tsai, C. C., Huang, R. N., Sung, H. W., \& Liang, H. C. (2000). In vitro evaluation of the genotoxicity of a naturally occurring crosslinking agent (genipin) for biologic tissue fixation. Journal of Biomedical Materials Research, 52(1), 58-65.

[27] Adamiak, K., \& Sionkowska, A. (2020). Current methods of collagen cross-linking. International Journal of Biological Macromolecules, 161, 550-560.
[28] Dotsika, E., Poutoukis, D., Michelot, J. L., \& Kloppmann, W. (2006). Stable isotope and chloride, boron study for tracing sources of boron contamination in groundwater: boron contents in fresh and thermal water in different areas in Greece. Water, Air, and Soil Pollution, 174(1), 19-32.

[29] Wang, J., Guo, K., Fan, X., Feng, G., \& Wei, C. (2018). Physicochemical properties of C-type starch from root tuber of Apios fortunei in comparison with maize, potato, and pea starches. Molecules, 23(9), 2132.

[30] Shaaban, M. M. (2010). Role of boron in plant nutrition and human health. American Journal of Plant Physiology, 5(5), 224-240.

[31] Angelova, L. V., Leskes, M., Berrie, B. H., \& Weiss, R. G. (2015). Selective formation of organo, organoaqueous, and hydro gel-like materials from partially hydrolysed poly (vinyl acetate) s based on different boron-containing crosslinkers. Soft Matter, 11(25), 50605066.

[32] Tantiwatcharothai, S., \& Prachayawarakorn, J. (2020). Property improvement of antibacterial wound dressing from basil seed (O. basilicum L.) mucilage-ZnO nanocomposite by borax crosslinking. Carbohydrate Polymers, 227, 115360 .

[33] Yin, Y., Li, J., Liu, Y., \& Li, Z. (2005). Starch crosslinked with poly (vinyl alcohol) by boric acid. Journal of Applied Polymer Science, 96(4), 1394-1397.

[34] Lu, H., Ji, N., Li, M., Wang, Y., Xiong, L., Zhou, L., Qui, L., Bian, X., \& Sun, Q. (2019). Preparation of borax cross-linked starch nanoparticles for improvement of mechanical properties of maize starch films. Journal of Agricultural and Food Chemistry, 67(10), 2916-2925.

[35] Gao, J., Liu, Y., \& Wang, F. (2001). Structure and properties of boron-containing bisphenol-A formaldehyde resin. European Polymer Journal, 37(1), 207-210.

[36] Uslu, I., Daştan, H., Altaş, A., Yayli, A., Atakol, O., \& Aksu, M. L. (2007). Preparation and characterization of PVA/boron polymer produced by an electrospinning technique. e-Polymers, 7(1).

[37] Staroszczyk, H. (2009). Microwave-assisted boration of potato starch. Polimery, 54, 31-41.

[38] Wang, J., Guo, K., Fan, X., Feng, G., \& Wei, C. (2018). Physicochemical properties of C-type starch from root tuber of Apios fortunei in comparison with maize, potato, and pea starches. Molecules, 23(9), 2132.

[39] Dome, K., Podgorbunskikh, E., Bychkov, A., \& Lomovsky, O. (2020). Changes in the crystallinity degree of starch having different types of crystal structure after mechanical pretreatment. Polymers, 12(3), 641.

[40] Zobel, H. F. (1988). Starch crystal transformations and their industrial importance. Starch-Stärke, 40(1), 1-7.

[41] Huber, C., Setoodeh Jahromy, S., Jordan, C., Schreiner, M., Harasek, M., Werner, A., \& Winter, F. (2019). Boric acid: a high potential candidate for thermochemical energy storage. Energies, 12(6), 1086.

[42] Schmidt, B., Rokicka, J., Janik, J., \& Wilpiszewska, K. (2020). Preparation and characterization of potato starch copolymers with a high natural polymer content for the removal of $\mathrm{Cu}$ (II) and Fe (III) from solutions. 
Polymers, 12(11), 2562.

[43] Ellis, R. P., Cochrane, M. P., Dale, M. F. B., Duffus, C. M., Lynn, A., Morrison, I. M., Prentice, R. D. M., Swanston, J. S. \& Tiller, S. A. (1998). Starch production and industrial use. Journal of the Science of Food and Agriculture, 77(3), 289-311.

[44] Heo, H., Lee, Y. K., \& Chang, Y. H. (2017). Rheological, pasting, and structural properties of potato starch by cross-linking. International journal of food properties, 20(2), 2138-2150.

[45] Kaur, L., Singh, J., \& Singh, N. (2006). Effect of crosslinking on some properties of potato (Solanum tuberosum L.) starches. Journal of the Science of Food and Agriculture, 86(12), 1945-1954.

[46] Singh, J., Kaur, L., \& McCarthy, O. J. (2007). Factors influencing the physico-chemical, morphological, thermal and rheological properties of some chemically modified starches for food applications-A review. Food hydrocolloids, 21(1), 1-22.
[47] Singh, A. V., \& Nath, L. K. (2012). Synthesis and evaluation of physicochemical properties of cross-linked sago starch. International Journal of Biological Macromolecules, 50(1), 14-18.

[48] Wongsagonsup, R., Pujchakarn, T., Jitrakbumrung, S., Chaiwat, W., Fuongfuchat, A., Varavinit, S., \& Suphantharika, M. (2014). Effect of cross-linking on physicochemical properties of tapioca starch and its application in soup product. Carbohydrate Polymers, 101, 656-665.

[49] Kim, H. Y., Oh, S. M., Bae, J. E., Yeom, J. H., Kim, B. Y., Kim, H. S., \& Baik, M. Y. (2017). Preparation and characterization of amorphous granular potato starches (AGPS) and cross-linked amorphous granular potato starches (CLAGPS). Carbohydrate Polymers, 178, 41-47.

[50] Kim, B. Y., \& Yoo, B. (2010). Effects of cross-linking on the rheological and thermal properties of sweet potato starch. Starch-Stärke, 62(11), 577-583. 